\title{
A numerical simulation of realistic top coal caving intervals under different top coal thicknesses in longwall top coal caving working face
}

Chuang Liu

Henan University of Engineering

Huamin Li ( $\sim$ lihm1957@163.com )

Henan Polytechnic University

\section{Research Article}

Keywords: thick coal seamm, longwall top coal caving working face, top coal caving interval, top coal recovery

Posted Date: February 26th, 2021

DOI: https://doi.org/10.21203/rs.3.rs-243080/v1

License: (c) (1) This work is licensed under a Creative Commons Attribution 4.0 International License.

Read Full License 


\section{Abstract}

In the process of longwall top coal caving, the selection of the top coal caving interval along the advancing direction of the working face has an important effect on the top coal recovery. To explore a realistic top coal caving interval of the longwall top coal caving working face, longwall top coal caving panel 8202 in the Tongxin Coal Mine is used as an example, and 30 numerical simulation models are established by using Continuum-based Distinct Element Method (CDEM) simulation software to study the top coal recovery with $4.0 \mathrm{~m}, 8.0 \mathrm{~m}, 12.0 \mathrm{~m}, 16.0 \mathrm{~m}, 20.0 \mathrm{~m}$ and $24.0 \mathrm{~m}$ top coal thicknesses and $0.8 \mathrm{~m}$, $1.0 \mathrm{~m}, 1.2 \mathrm{~m}, 1.6 \mathrm{~m}$ and $2.4 \mathrm{~m}$ top coal caving intervals. The results show that with an increase in the top coal caving interval, the single top coal caving amount increases. The top coal recovery is the highest with a $0.8 \mathrm{~m}$ top coal caving interval when the thickness of the top coal is less than $4.0 \mathrm{~m}$, and it is the highest with a $1.2 \mathrm{~m}$ top coal caving interval when the coal seam thickness is greater than $4.0 \mathrm{~m}$. These results provide a reference for the selection of a realistic top coal caving interval in thick coal seam caving mining.

\section{Introduction}

Top coal caving mining technology started in the 1980 s and continues to this day ${ }^{1,2}$. Longwall top coal caving (LTCC) mining consists of two processes: shearer cutting in front of a hydraulic support and top coal caving behind a hydraulic support. The parameters of the top coal caving interval (TCCI) in the process of top coal caving behind a hydraulic support have an important impact on the top coal recovery 3,4 . The top coal recovery is an important index to evaluate the success of top coal caving mining. Therefore, improving the top coal recovery is an important technical problem faced by LTCC mining ${ }^{5-7}$.

Wang, J.C., et al. derived an equation of a possible caving ellipsoid and an actual caving ellipsoid on the basis of caving ellipsoid theory and analyzed the optimization calculation method of caving parameters along the dip direction of the working face ${ }^{8-10}$. Sun, L.H., et al., using a similar simulation, constructed 15 coal drawing models according to different TCCls, coal drawing sequences, coal drawing methods and coal seam dip angles; they compared and analyzed the influence of different coal drawing conditions on the top coal recovery and the movement of top coal and gangue, and they concluded that the top coal recovery of the working face was the highest when a single round sequential coal drawing method from bottom to top was adopted in the working face dip direction ${ }^{11,12}$. Li, H.J., et al., with the method of orthogonal experimental design, used the top coal crushing coefficient as the index and the hydraulic support height, hydraulic support length and TCCl of the hydraulic support as the influencing factors to carry out range and variance analyses on the simulation results of PFC 2D and obtain the sensitivity of each influencing factor on the top coal recovery ${ }^{13-15}$.

Based on CDEM numerical simulation software, this study uses the 8202 LTCC working face of the Tongxin Coal Mine. According to the top coal caving law along the strike direction of the LTCC working face, this paper establishes a numerical simulation model along the strike direction of the working face, 
systematically simulates the top coal recovery of the LTCC working face under different top coal thickness and TCCls, and summarizes the best TCCI under different top coal thickness for the maximum top coal recovery according to the results of the numerical simulation.

\section{Numerical Simulation Model}

\subsection{Establishment of the numerical simulation model}

In this study, CDEM software is used to simulate the top coal caving during the mining process of panel 8202. The CDEM software was developed by the Institute of Mechanics, Chinese Academy of Sciences, and its algorithm couples the finite element method (FEM) and the discrete element method (DEM) ${ }^{16}$.

To research the influence of the TCCl on the top coal recovery under different top coal thickness conditions, according to the specific size parameters of the ZF15000/27.5/42 low-level caving hydraulic support used in the 8202 LTCC working face of the Tongxin Coal Mine, simplified processing is first carried out to establish a two-dimensional numerical simulation model of the caving hydraulic support, as shown in Fig. 1.

The length of the numerical simulation model is $180.0 \mathrm{~m}$, the reserved length of the left and right boundary is $32.0 \mathrm{~m}$, and the left and right sides and the lower part of the model are fixed. In the model, the coal cutting height of the shearer is $3.9 \mathrm{~m}$, and the top coal with different thicknesses is located above the shearer cutting coal seam. The established top coal thickness is $4.0 \mathrm{~m}, 8.0 \mathrm{~m}, 12.0 \mathrm{~m}, 16.0 \mathrm{~m}$, $20.0 \mathrm{~m}$ and $24.0 \mathrm{~m}$, the immediate roof (gangue) is $3.0 \mathrm{~m}$ thick, and the upper part of the immediate roof is $7.0 \mathrm{~m}$ thick and is composed of hard rock. The model is simulated from left to right, and the first 20.0 $\mathrm{m}$ of the simulation does not cave the top coal but only cuts the coal seam with a shearer cutting height. After $20.0 \mathrm{~m}$, while the shearer cuts the coal seam, the top coal is recovered in the corresponding area of the rear scraper conveyor. During the simulation process, the gangue falling into the top coal area of the rear scraper conveyor is monitored as the standard to move the frame. That is, for the gangue moving frame, the established numerical simulation model is shown in Fig. 2.

\subsection{Model parameters}

According to different forces on the top coal in different rock layers, the degree of particle fragmentation increases from top to bottom. The top coal particles of the established numerical simulation model decrease sequentially from top to bottom. The particle size setting of each rock layer in the model is shown in Table 1, and the mechanical parameters of the particles in the model are shown in Table 2.

\section{Numerical Simulation Of The Top Coal Caving Interval}

The selection of the TCCI in the LTCC working face has a great influence on the top coal recovery. Both too large and too small of a TCCI leads to a decrease in the top coal recovery. Based on the current LTCC working face, the shearer cutting depth is mainly $0.6 \mathrm{~m}$ and $0.8 \mathrm{~m}$, while very few adopt $1.0 \mathrm{~m}$, and the 
integer multiple of the shearer cutting depth is selected as the TCCl. A large TCCI is poorly applied in production practice because the top coal loss is substantial. Therefore, this paper focuses on the simulation of "one cutting and one caving" and "two cuttings and one caving" top coal caving intervals, that is, $0.8 \mathrm{~m}, 1.0 \mathrm{~m}, 1.2 \mathrm{~m}$ and $1.6 \mathrm{~m}$ top coal caving intervals.

For the large TCCl, only $2.4 \mathrm{~m}$ is simulated. This paper simulates and analyzes the top coal recovery of top coal with thicknesses of $4.0 \mathrm{~m}, 8.0 \mathrm{~m}, 12.0 \mathrm{~m}, 16.0 \mathrm{~m}, 20.0 \mathrm{~m}$, and $24.0 \mathrm{~m}$ under 5 different TCCl conditions. Taking the top coal thicknesses of $4.0 \mathrm{~m}, 12.0 \mathrm{~m}$, and $20.0 \mathrm{~m}$ as examples, the effect of the $\mathrm{TCCl}$ on the top coal recovery under different top coal thickness conditions is explained in detail.

\subsection{Simulation of the top coal recovery of a 4.0 m thickness under different top coal caving intervals}

Fig. 3 shows the inversion results of the first three steps of the top coal caving bodies of the $4.0 \mathrm{~m}$ thick top coal under different TCCls. Fig. 3 shows that there is no obvious difference in the first three steps of the top coal recovery of $4.0 \mathrm{~m}$ thick top coal under different TCCls. When there is no gangue boundary on the left side of the caving window, the first step of the top coal caving amount under different TCCI conditions is relatively large, and the caving body is cut into an oval-like shape.

In the subsequent second and third top coal caving steps, due to the large top coal caving amount in the first step, the gangue above the top coal moves to the vicinity of the top coal caving window. After the first top coal caving is completed, the gangue is close to the upper left of the top coal caving window. When the top coal caving window is opened and the top coal is cleaved again, it is easy to cause the gangue near the top coal caving window to mix in advance and end the current top coal caving process. Therefore, the recoveries in the second and third top coal caving steps are greatly reduced compared with the recovery in the first top coal caving step. Only a few top coal particles are recovered before the gangue reaches the recovery area of the rear scraper conveyor, and there is no obvious shape of the top coal drawing body.

The top coal loss and coal-gangue interbeds of the $4.0 \mathrm{~m}$ thick top coal under different TCCI conditions are organized as shown in Fig. 4. Under different TCCI conditions, the top coal loss and coal gangue interbeds are different. Fig. 4 clearly shows that less top coal is lost and the coal-gangue interbeds are thinner under the $0.8 \mathrm{~m} \mathrm{TCCl}$. The most top coal is lost under the $2.4 \mathrm{~m} \mathrm{TCCl}$. Under different TCCls, the descending gangue interface is jagged with no fixed shape.

\subsection{Simulation of the top coal recovery of a $12.0 \mathrm{~m}$ thickness under different top coal caving intervals}

The inversion results of the first three steps of top coal caving bodies with $12.0 \mathrm{~m}$ thick top coal intervals under different $\mathrm{TCCl}$ conditions are shown in Fig. 5. The top coal recoveries of the $12.0 \mathrm{~m}$ thick top coal and $4.0 \mathrm{~m}$ thick top coal in the first three steps are basically the same. The top coal recovered in the first step is large, and the shape of the discharge body is an ellipse. The top coal caving amounts recovered in the second and third steps are small, and there is no obvious discharge body shape. In the simulation of the $2.4 \mathrm{~m} \mathrm{TCCl}$, the phenomenon of the top coal arching above the caving window appears in the first top 
coal caving process, which blocks the caving window, resulting in a relatively small top coal recovery. The relative amount of top coal recovered during the second and third caving operations increases. Under different TCCls, except that the top coal recovery of the $2.4 \mathrm{~m} \mathrm{TCCl}$ is different from other groups due to the arch formation of the top coal, there is no obvious difference in the first three steps of the top coal recovery of other groups.

The top coal loss and coal-gangue interbeds of the $12.0 \mathrm{~m}$ thick top coal under different TCCls are shown in Fig. 6. Compared with the coal-gangue interbeds of the $4.0 \mathrm{~m}$ thick top coal under different TCCls, the coal-gangue interbed interface of the $12.0 \mathrm{~m}$ thick top coal is obvious, and the horizontal distance between two adjacent coal-gangue interbedding planes is $10-12 \mathrm{~m}$. The top coal loss under the $0.8 \mathrm{~m}, 1.0$ $\mathrm{m}$ and $1.2 \mathrm{~m} \mathrm{TCCls}$ is obviously less than that under the $1.6 \mathrm{~m}$ and $2.4 \mathrm{~m}$ TCCls.

\subsection{Simulation of the top coal recovery of a $\mathbf{2 0 . 0} \mathrm{m}$ thickness under different top coal caving intervals}

Fig. 7 shows the inversion results of the top coal caving bodies with a thickness of $20.0 \mathrm{~m}$ under different TCCls. The thickness of the $20.0 \mathrm{~m}$ top coal is relatively large, and the top coal transportation trajectory is long. Compared with the top coal thicknesses of $4.0 \mathrm{~m}$ and $12.0 \mathrm{~m}$, a coal arch above the caving window more easily forms under a thickness of $20.0 \mathrm{~m}$, blocking the caving window and making the top coal unable to be recovered smoothly. Different degrees of top coal arching occur during the first coal caving step of thicknesses of $1.6 \mathrm{~m}$ and $2.4 \mathrm{~m}$ TCCls, which reduces the top coal recovery. Under the $1.6 \mathrm{~m}$ and $2.4 \mathrm{~m}$ thick TCCl conditions, the recovery of the top coal in the second and third caving steps increases. The recovery and shape of the top coal drawing body under the conditions of the other TCCI groups are similar.

The top coal loss and coal-gangue interbeds of $20.0 \mathrm{~m}$ thick top coal under different TCCls are shown in Fig. 8. Due to the large thickness of the top coal and the long interface of the coal-gangue interbeds, during the caving process, the gangue above the caving window easily reaches the caving window before it reaches the top coal above the caving window, leading to the end of top coal caving. Therefore, the absolute amount of top coal loss is relatively large in the process of thick top coal caving. The horizontal distance between two adjacent coal gangue interlayers is $16-20 \mathrm{~m}$. Fig. 8 also shows that the top coal loss under the $1.2 \mathrm{~m}$ thick TCCl is significantly less than that of the other four groups, and the top coal losses under the $1.6 \mathrm{~m}$ and $2.4 \mathrm{~m}$ thick TCCls are the largest.

\section{Statistical Calculation Of The Top Coal Recovery}

To understand the recovery of the top coal in each top coal caving step under different TCCls, the top coal thicknesses of $4.0 \mathrm{~m}, 12.0 \mathrm{~m}$ and $20.0 \mathrm{~m}$ were calculated. The recovery amount of top coal in a caving step is shown in Figs. 9-11. The top coal recovery in a single caving step under various top coal thicknesses generally increases with increasing TCCls. For the same top coal thickness, the dispersion degree of the top coal recovery is different in different TCCls. The mean square deviation of the top coal recovery of the $4.0 \mathrm{~m}$ thick top coal is $2.90,3.11,3.38,4.19$ and 4.27 under the thicknesses of $0.8 \mathrm{~m}, 1.0$ $\mathrm{m}, 1.2 \mathrm{~m}, 1.6 \mathrm{~m}$ and $2.4 \mathrm{~m} \mathrm{TCCl}$, respectively. The mean square deviation of the top coal recovery of the 
$12.0 \mathrm{~m}$ thick top coal is $12.23,13.64,15.64,16.37$, and 15.10 ; the mean square deviation of the top coal recovery of the $20.0 \mathrm{~m}$ thick top coal is $23.40,31.48,31.41,31.22$, and 37.55 . The mean square deviation of the top coal drawing amount in each caving step increases with the increasing TCCI and top coal thickness; that is, the larger the TCCI and top coal thickness are, the more unbalanced the top coal recovery of each top coal caving window is.

To compare the top coal recovery of different top coal thicknesses under different TCCls, it is necessary to count and calculate the top coal recovery in the process of top coal caving. The total area of the top coal is calculated by the number of top coal particles in the caving area and the boundary area of $5.0 \mathrm{~m}$ affected by the caving on the left and right sides, as shown in Fig. 12. The top coal recovery is the ratio of the total area of the top coal particles falling into the rear scraper conveyor to the total area of the top coal. The top coal recoveries of $4.0 \mathrm{~m}, 8.0 \mathrm{~m}, 12.0 \mathrm{~m}, 16.0 \mathrm{~m}, 20.0 \mathrm{~m}$ and $24.0 \mathrm{~m}$ top coal thicknesses under different TCCls are calculated. The statistical results are shown in Fig. 13.

In Fig. 13, the optimal TCCI for the top coal thickness of $4.0 \mathrm{~m}$ is $0.8 \mathrm{~m}$, and the optimal TCCI for the remaining top coal thickness is $1.2 \mathrm{~m}$. Among the TCCls, the top coal recovery of the $4.0 \mathrm{~m}$ thick top coal under the $1.2 \mathrm{~m} \mathrm{TCCl}$ is only $1.53 \%$ lower than that of the $0.8 \mathrm{~m}$ thick top coal. Under the $1.2 \mathrm{~m}$ thick TCCl, with the increase in the top coal thickness, the recovery of the top coal increases more obviously compared with other TCCls. At present, the cutting depth of the shearer in the LTCC working face is typically $0.8 \mathrm{~m}$, and the TCCl can be $0.8 \mathrm{~m}, 1.6 \mathrm{~m}$ and $2.4 \mathrm{~m}$. According to the simulation results, the best $\mathrm{TCCl}$ is $0.8 \mathrm{~m}$. If the TCCl can be increased to $1.2 \mathrm{~m}$, the top coal recovery can be further improved.

\section{Conclusion}

According to the geological conditions of the 8202 fully mechanized caving face in the Tongxin Coal Mine, a numerical simulation model along the advancing direction of the working face is established, and the different TCCls of the LTCC working face are simulated and compared. The main conclusions are as follows.

(1) The amount of top coal recovered in a single top coal caving step under different top coal thicknesses generally increases with increasing TCCls.

(2) After top coal caving under different top coal thicknesses, the coal-rock interface has an irregular jagged shape.

(3) By simulating the top coal caving process with different top coal thicknesses of $0.8 \mathrm{~m}, 1.0 \mathrm{~m}, 1.2 \mathrm{~m}$, $1.6 \mathrm{~m}$ and $2.4 \mathrm{~m}$, it is concluded that the mean square deviation of the top coal drawing amount in each unit of distance moved generally increases with the increase in the TCCl and top coal thickness; this indicates that the smaller the TCCl and the thickness of the top coal, the smaller the difference in the amount of top coal recovered in each caving window, and the larger the TCCI and the top coal thickness is, the greater the difference in the caving amount in each caving window is. 
(4) Under different top coal thickness conditions, when the thickness of the top coal is less than $4.0 \mathrm{~m}$ and the TCCI is $0.8 \mathrm{~m}$, the top coal recovery is the highest; when the coal seam thickness is greater than $4.0 \mathrm{~m}$ and the $\mathrm{TCCl}$ is $1.2 \mathrm{~m}$, the top coal recovery is the highest.

\section{Declarations}

\section{Acknowledgments}

This research is funded by the Chinese Natural Science Committee under grant No. 2018 YFC0604502 and Ph.D. Fund of Henan University of Engineering under grant No. DKJ2019001. The authors are grateful for their support.

\section{Author contributions}

H.M. Li suggested the project direction; C. Liu performed the numerical simulation and analyzed the results. C. Liu organized and wrote the paper. All authors reviewed and approved the manuscript.

\section{Competing interests}

The authors declare no competing interests.

\section{Additional information}

Correspondence and requests for materials should be addressed to H.M. Li.

\section{References}

1. Zhong, T. Research on structural characteristics of coal and gangue flowing field and top coal loss regulation in super thick coal seam using top coal caving method. Ph.D. dissertation, Xuzhou, China University of Mining and Technology. 47-64(2015).

2. Wang, J.C., et al. Laboratory and field validation of a LTCC recovery prediction model using relative size of the top coal blocks. Bull. Eng. Geo. Envi. 2020 (in press). DOI: 10.1007/s10064-020-01970-0.

3. Sun, L.H., et al. Top-coal caving process and movement characters of fully mechanized caving face in steeply dipping thick seam. J. M. Safe. Eng. 33(2), 208-213(2016). DOI:

10.13545/j.cnki.jmse.2016.02.003.

4. Liu C.Y., Huang, B.X. and Wu F.F. Technical parameters of drawing and coal-gangue field movements of a fully mechanized large mining height top coal caving working face. Min. Sci. Tech. 19, 549555(2009).

5. Liu, C., et al. Method of synergetic multi-windows caving in longwall top coal caving working face. J. China Coal Soc. 44(9), 2632-2640(2019). DOI: 10.13225/j.cnki.jccs.2018.1278.

6. Song, Z.Y., Konietzky, H. \& Herbst, M. Drawing mechanism of fractured top coal in longwall top coal caving. Int. J. Rock Mech. Min. Sci. 130, (2020). DOI: 10.1016/j.ijrmms.2020.104329. 
7. Wang, J.C., Yin, Z.Z. The basic mechanics problems and the development of longwall top-coal caving technique in China. ISRM International Symposium 2000.

8. Zhang, N.B. and Liu C.Y. Arch structure effect of the coal gangue flow of the fully mechanized caving in special thick coal seam and its impact on the loss of top coal. Int. J. Min. Sci. Tech. 26(3), 593599(2016).

9. Wang, J.C.. Engineering practice and theoretical progress of top-coal caving mining technology in China. J. China Coal Soc. 43(1), 43-51(2018). DOI: 10.13225/j.cnki.jccs.2017.4101.

10. Wang, J.C., Wei, W.J. \& Zhang, J.W. Theoretical description of drawing body shape in an inclined seam with longwall top coal caving mining. Int. J. Coal Sci. Tech. 7(1), 182-195(2020). DOI: 10.1007/s40789-019-00286-z.

11. Tian, D., et al. Study on relationship between coal caving step distance and top coal caving recovery rate based on ellipsoid theory. Coal Sci. Tech. 43(3), 51-53, 143(2015). DOI: 10.13199/j.cnki.cst.2015.05.013.

12. Bao, Y.S., Study on key technology of intelligent control in fully-mechanized top coal caving face in extra thick seam. Coal Sci. Tech. 48(7), 55-61(2020). DOI: 10. 13199/j.cnki.cst.2020.07.004.

13. Li, H.J., Pan, R.K. and Zhang, Z.Y. Analysis on influencing factors of release rate of top coal caving mining in large mining height. Coal Tech. 35(2), 48-49(2016). DOI: 10.13301/j.cnki.ct.2016.02.018.

14. Yang, S.L., Wei, W.J. \& Zhang, J.W. Top coal movement law of dynamic group caving method in LTCC with an inclined seam. Min. Metal. Explore. 37(5), 1545-1555(2020). DOI: 10.1007/s42461-02000254-1.

15. Wang, J.C., Wang, Z.H. \& Li, Y. Longwall top coal caving mechanisms in the fractured thick coal seam. Int. J. Geom. 20(8), August 1, 2020. DOI: 10.1061/(ASCE)GM.1943-5622.0001722.

16. Ju Y, et al. CDEM-based analysis of the 3D initiation and propagation of hydrofracturing cracks in heterogeneous glutenites. J. Nat. Gas. Sci. Eng. 35, 614-623(2016).

\section{Tables}

Table 1 Particle diameter and height of the numerical model rock layer

\begin{tabular}{lcc}
\hline Rock layer & Diameter of particles /m & Height/m \\
\hline Hard rock & 0.4 & 7.0 \\
Gangue & 0.3 & 3.0 \\
Upper top-coal & 0.25 & -- \\
Middle upper top coal & 0.2 & - \\
Middle top coal & 0.2 & - \\
Middle lower top coal & 0.15 & - \\
Lower top coal & 0.1 & - \\
Cutting coal seam & 0.2 & 3.9 \\
\hline
\end{tabular}


Table 2 Particle mechanical parameters of coal and roof rock strata

\begin{tabular}{ccccccc}
\hline Rock layer & $\begin{array}{c}\text { Unit weight } \\
\square \mathrm{kN} / \mathrm{m}^{3} \square\end{array}$ & $\begin{array}{c}\text { Elasticity modulus } \\
\square \mathrm{GPa} \square\end{array}$ & Poisson's ratio & $\begin{array}{c}\text { Tensile strength } \\
\square \mathrm{MPa} \square\end{array}$ & $\begin{array}{c}\text { Cohesion } \\
\square \mathrm{MPa} \square\end{array}$ & $\begin{array}{c}\text { Friction angle } \\
\square \square\end{array}$ \\
\hline 3ロ5\# coal seam & 13.4 & 2.8 & 0.34 & 0.5 & 0.9 & 28.6 \\
Carbon mudstone & 15.6 & 4.4 & 0.29 & 0.9 & 15.9 & 33.7 \\
Sandy mudstone & 25.3 & 24.2 & 0.25 & 4.7 & 42.4 & 41.3 \\
\hline
\end{tabular}

\section{Figures}

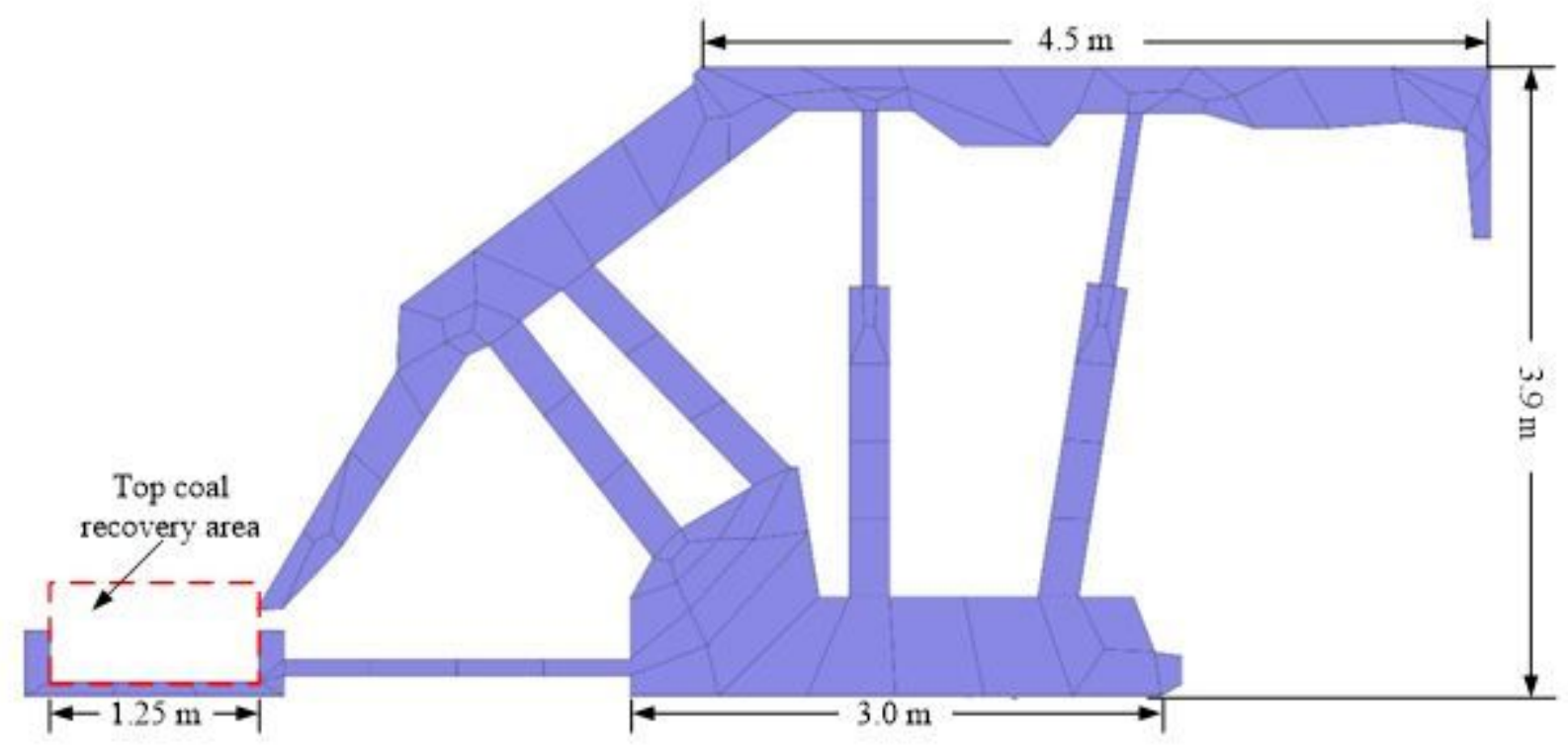

\section{Figure 1}

Model and size of shield used in numerical simulation

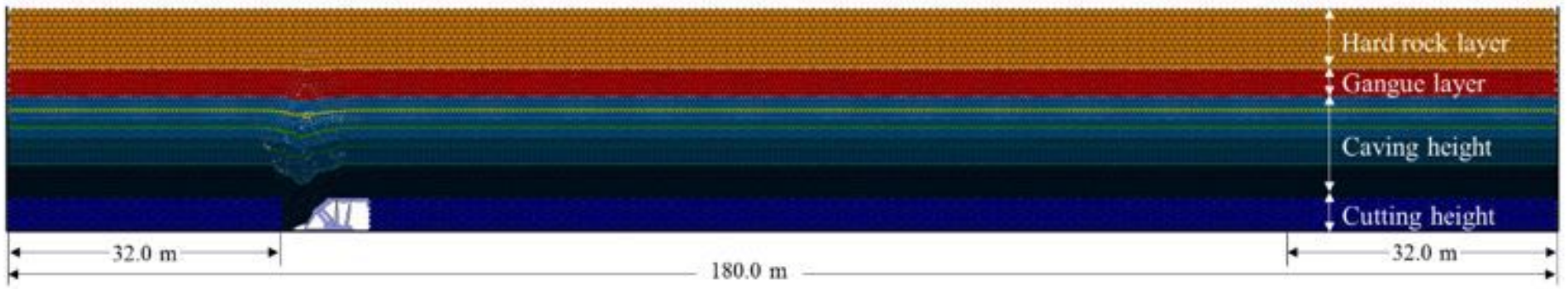

\section{Figure 2}

Numerical simulation model along the strike direction in LTCC working face 

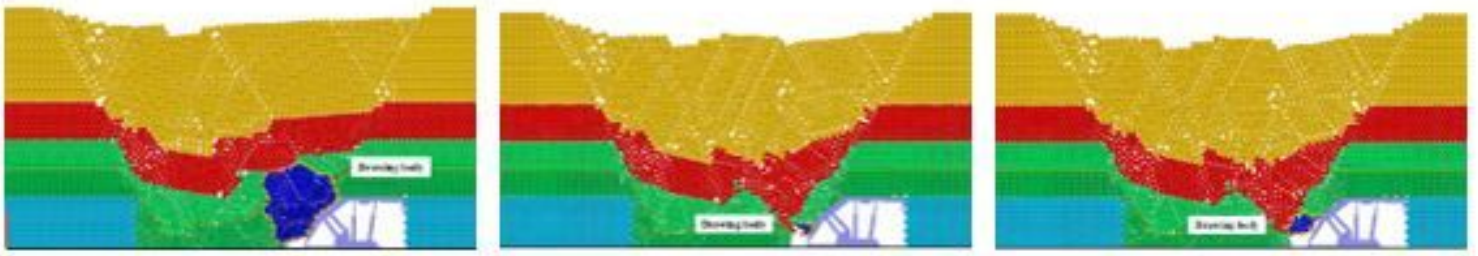

(a) $0.8 \mathrm{~m} \mathrm{TCCI}$
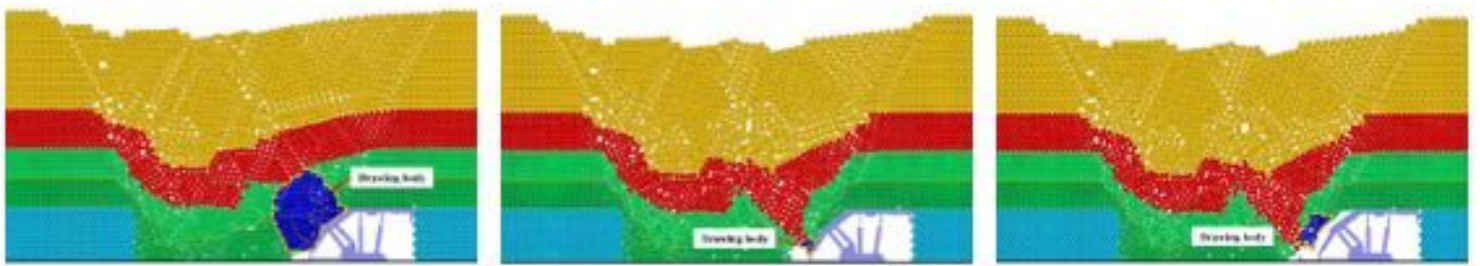

(b) $1.0 \mathrm{~m} \mathrm{TCCI}$
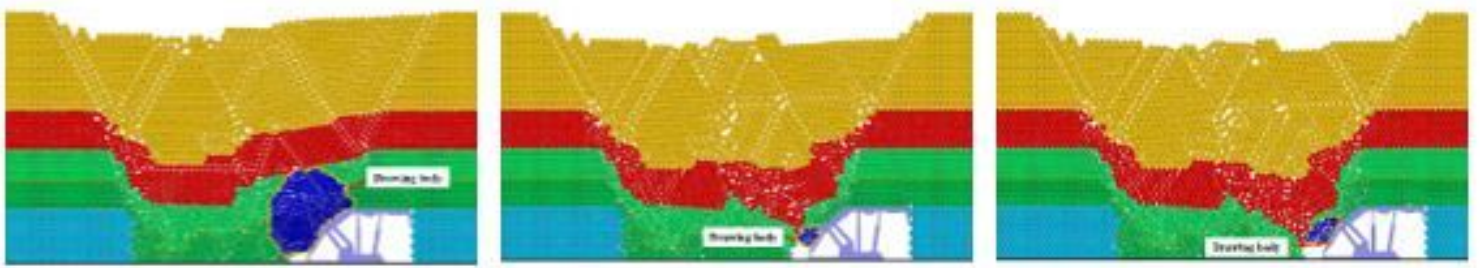

(c) $1.2 \mathrm{~m} \mathrm{TCCI}$
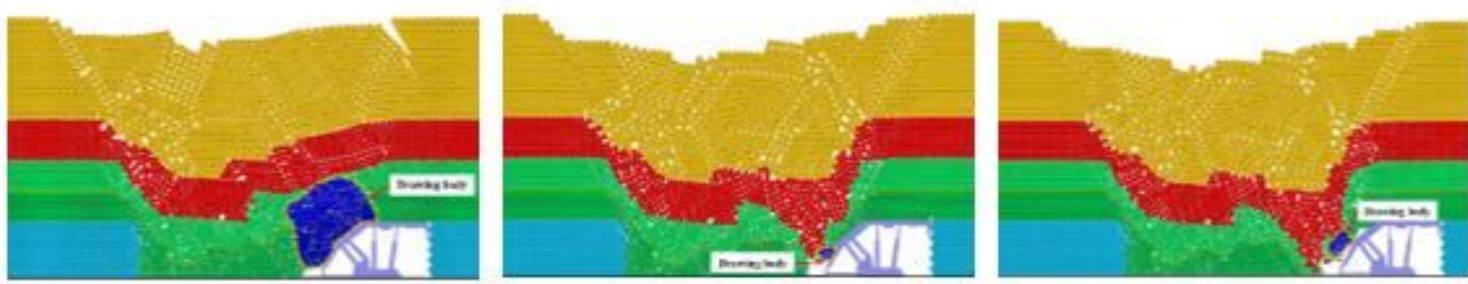

(d) $1.6 \mathrm{~m} \mathrm{TCCI}$
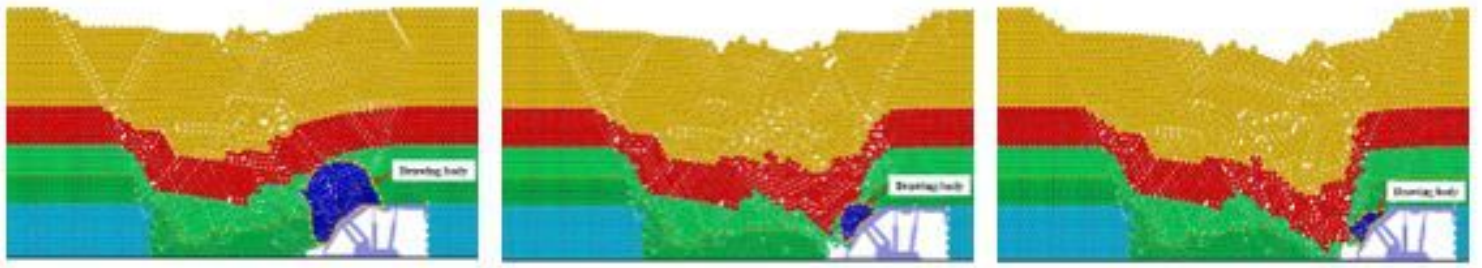

(e) $2.4 \mathrm{~m} \mathrm{TCCI}$

\section{Figure 3}

Inversion results of the first three top coal release body in different coal-drawing interval under $4.0 \mathrm{~m}$ top coal thickness 


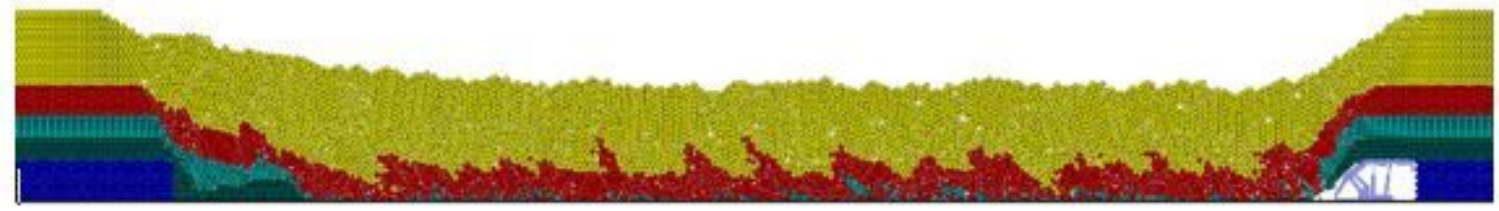

(a) $0.8 \mathrm{~m} \mathrm{TCCI}$

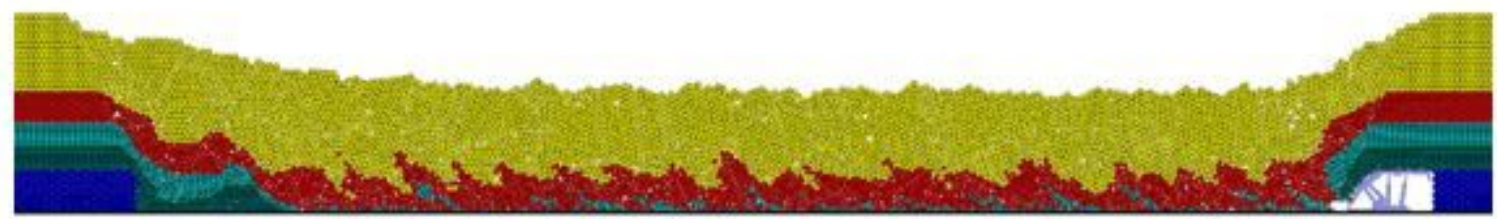

(b) $1.0 \mathrm{~m} \mathrm{TCCI}$

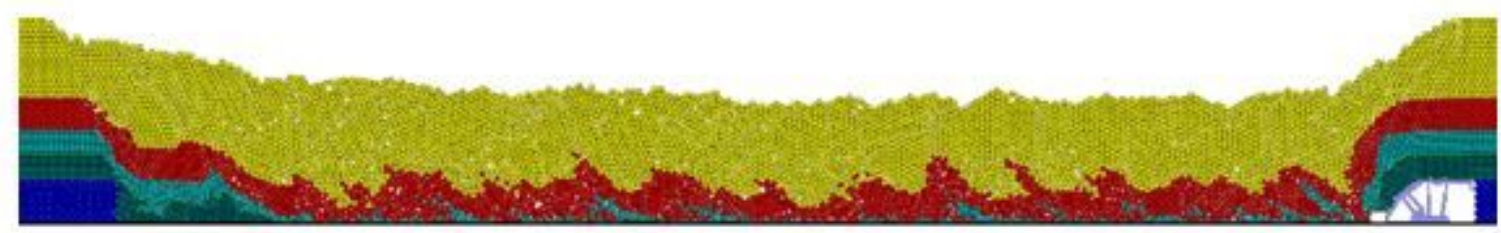

(c) $1.2 \mathrm{~m} \mathrm{TCCI}$

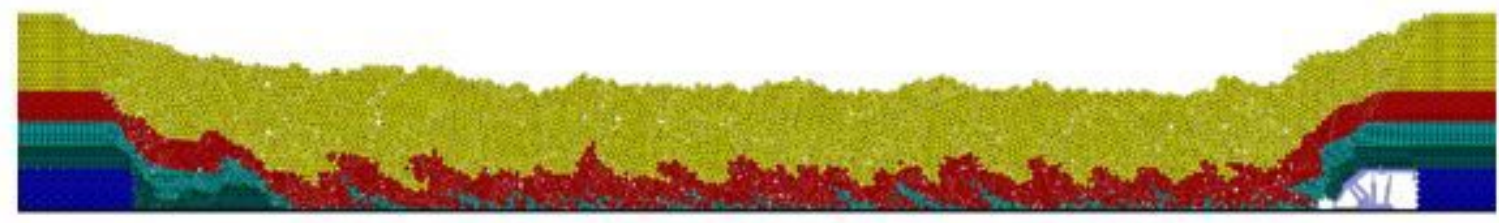

(d) $1.6 \mathrm{~m} \mathrm{TCCI}$

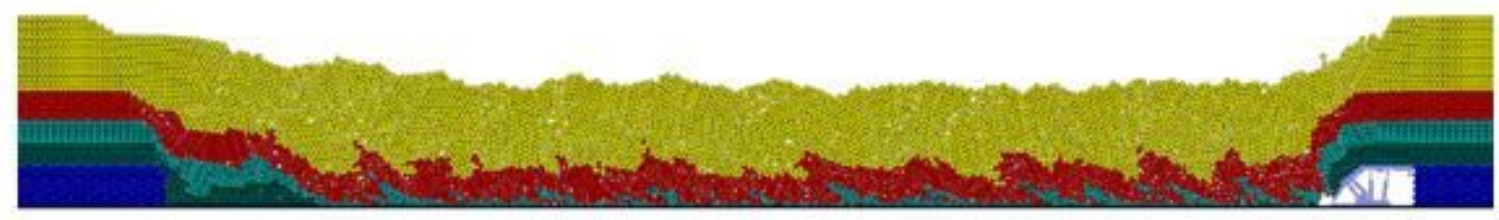

(e) $2.4 \mathrm{~m} \mathrm{TCCI}$

Figure 4

Loss of top coal in different coal-drawing interval under $4.0 \mathrm{~m}$ top coal thickness 

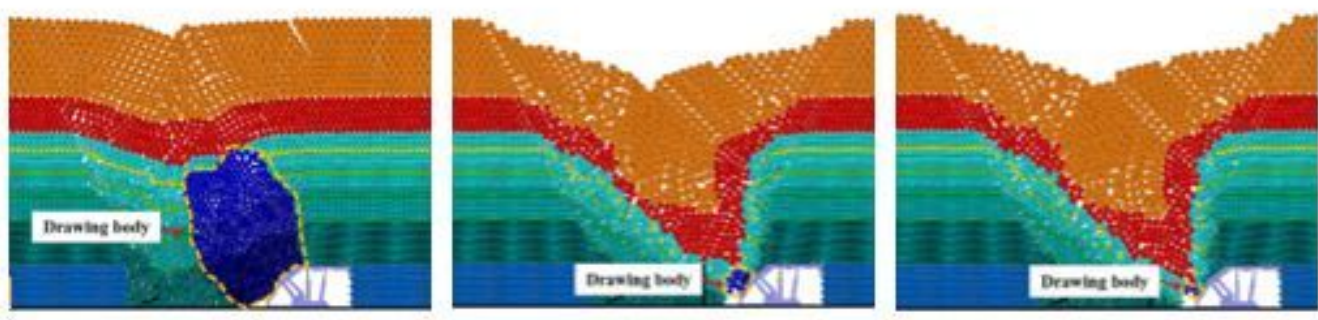

(a) $0.8 \mathrm{~m} \mathrm{TCCI}$
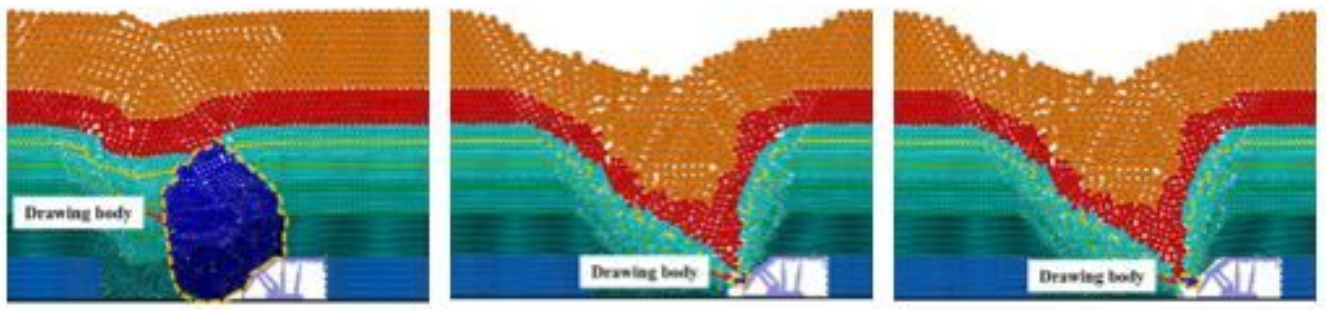

(b) $1.0 \mathrm{~m}$ TCCI
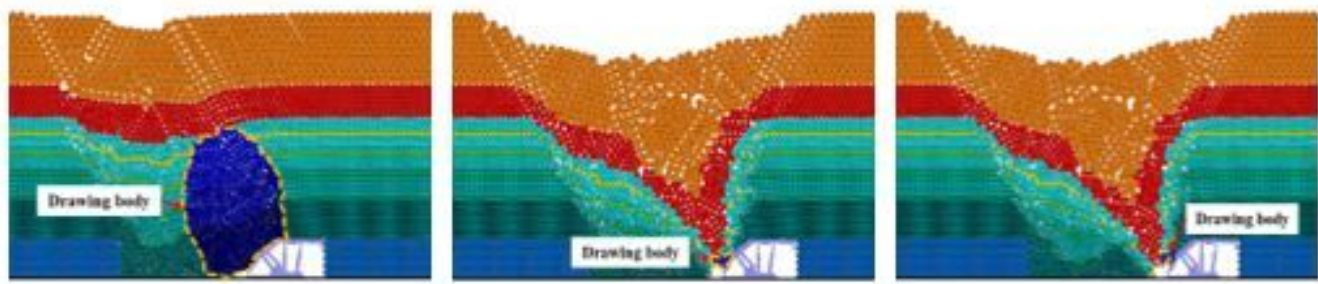

(c) $1.2 \mathrm{~m} \mathrm{TCCI}$
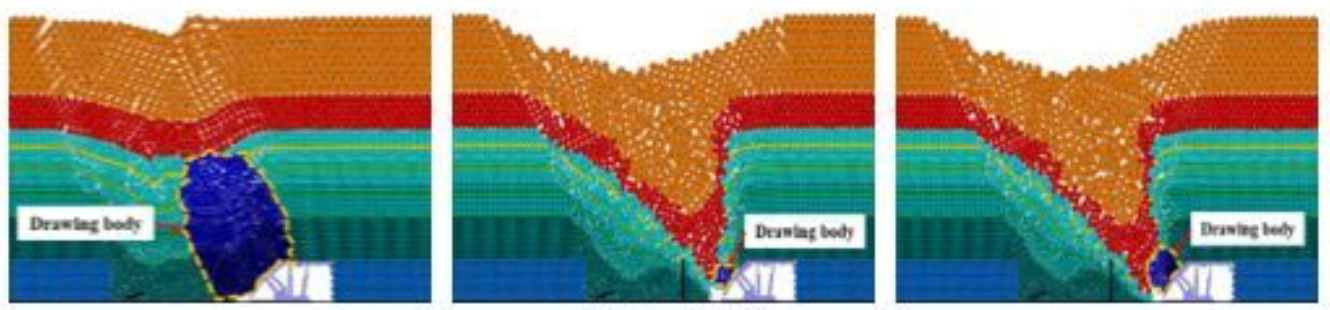

(d) $1.6 \mathrm{~m}$ TCCI
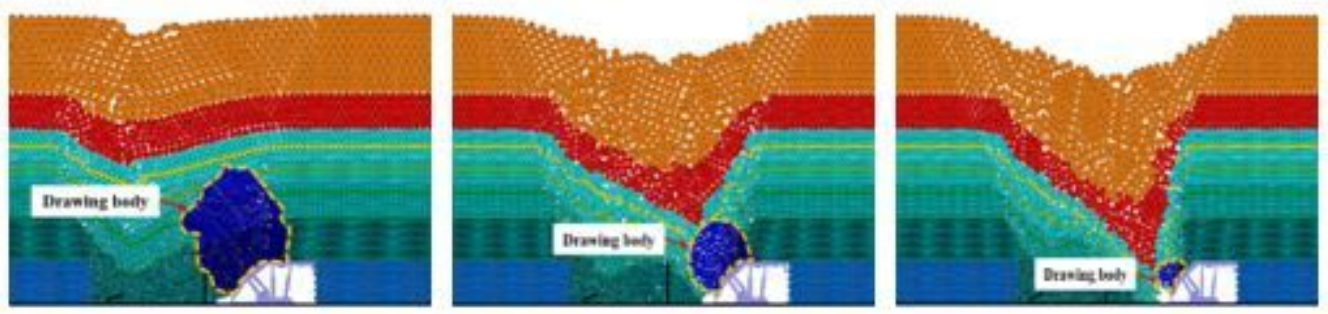

(e) $2.4 \mathrm{~m}$ TCCI

Figure 5

Inversion results of the first three top coal release body in different coal-drawing interval under $12.0 \mathrm{~m}$ top coal thickness 


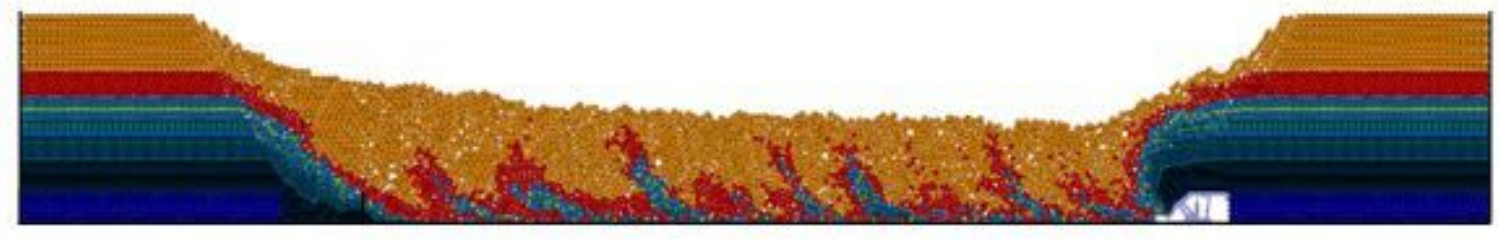

(a) $0.8 \mathrm{~m} \mathrm{TCCI}$

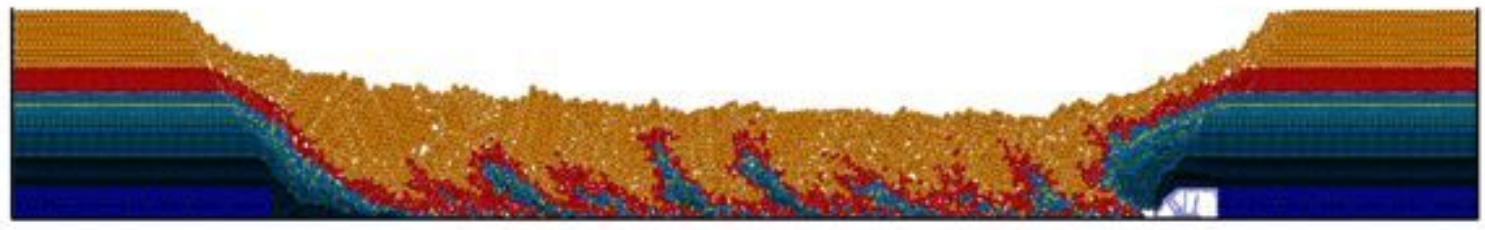

(b) $1.0 \mathrm{~m} \mathrm{TCCI}$

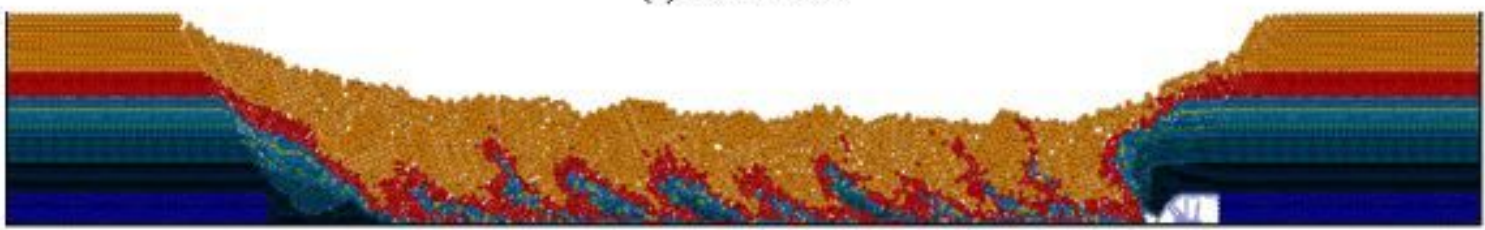

(c) $1.2 \mathrm{~m} \mathrm{TCCI}$

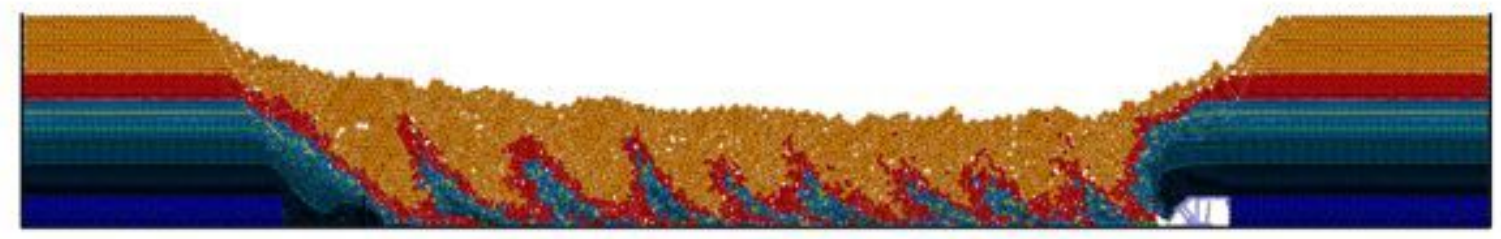

(d) $1.6 \mathrm{~m} \mathrm{TCCI}$

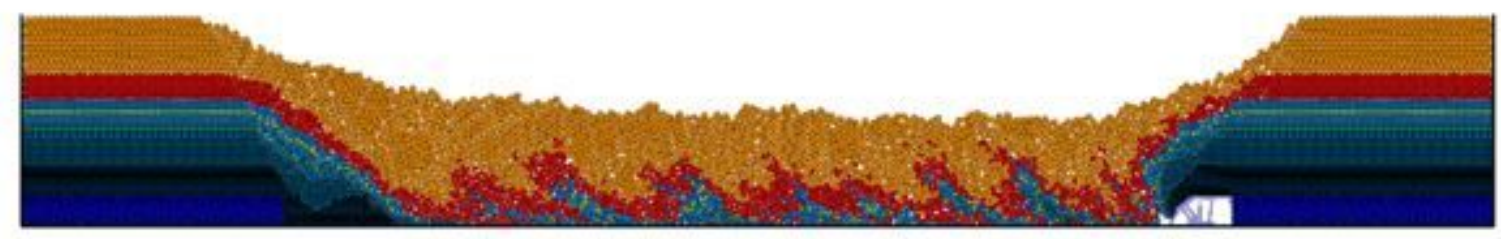

(e) $2.4 \mathrm{~m} \mathrm{TCCI}$

Figure 6

Loss of top coal in different coal-drawing interval under $12.0 \mathrm{~m}$ top coal thickness 

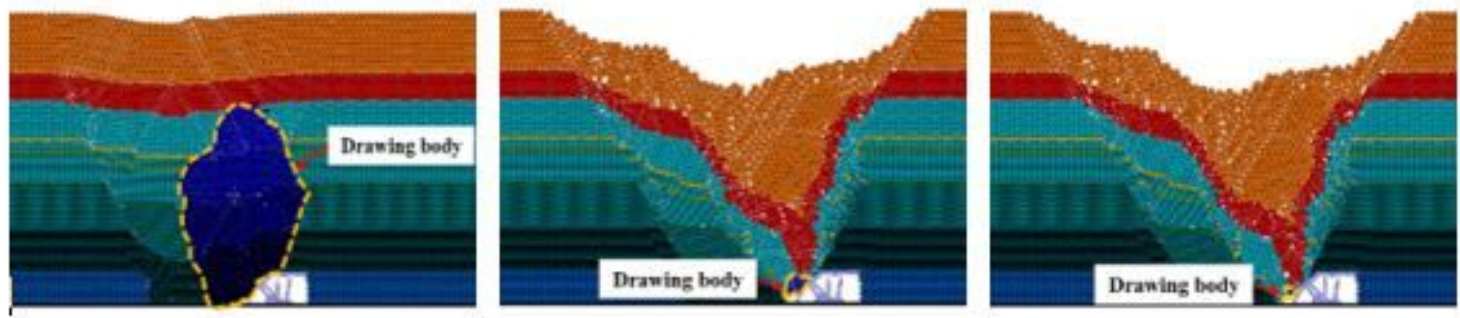

(a) $0.8 \mathrm{~m} \mathrm{TCCI}$
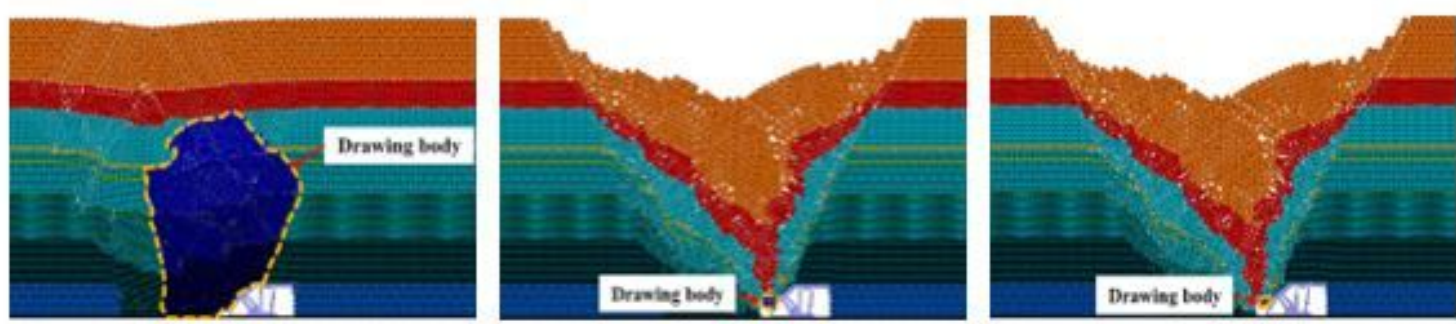

(b) $1.0 \mathrm{~m} \mathrm{TCCI}$
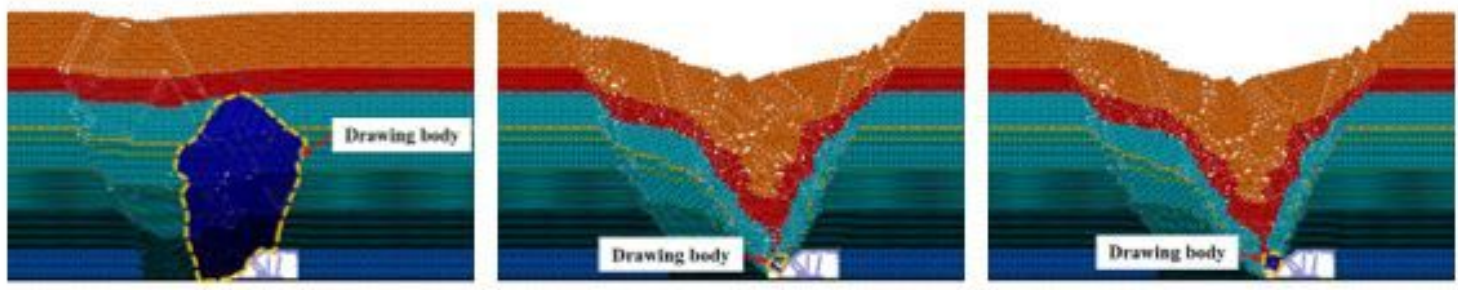

(c) $1.2 \mathrm{~m} \mathrm{TCCI}$
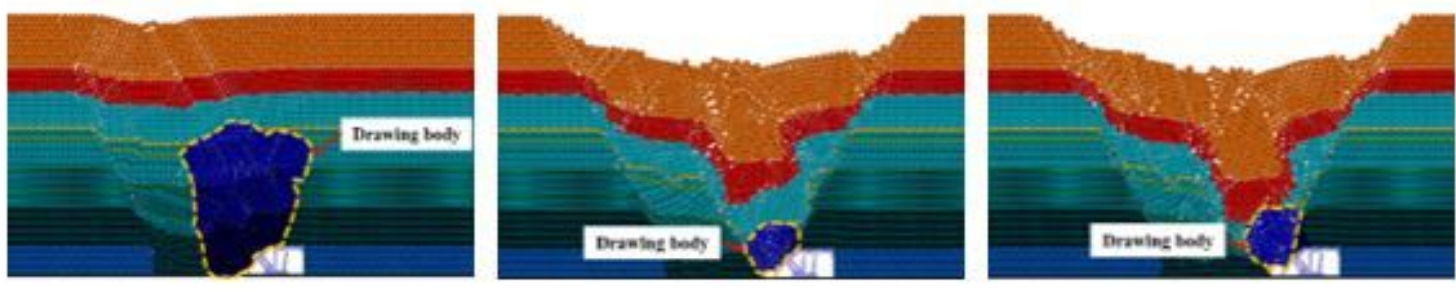

(d) $1.6 \mathrm{~m} \mathrm{TCCI}$
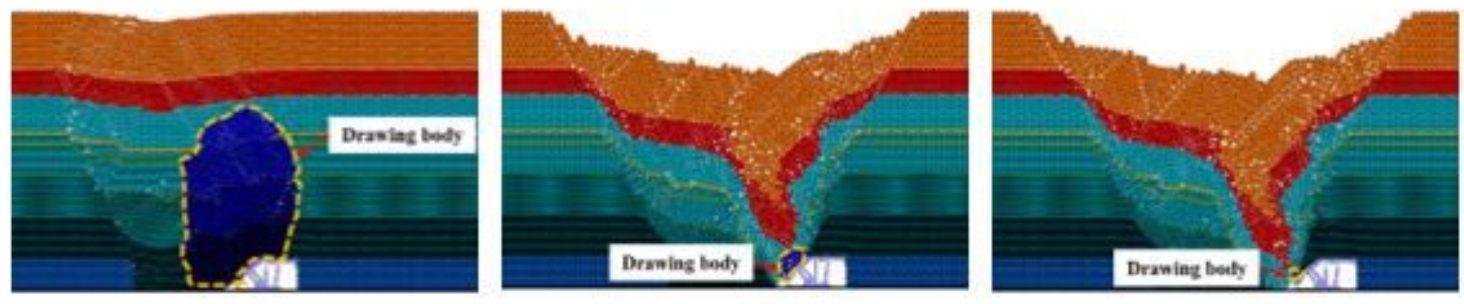

(e) $2.4 \mathrm{~m}$ TCCI

Figure 7

Inversion results of the first three top coal release body in different coal-drawing interval under $20.0 \mathrm{~m}$ top coal thickness 


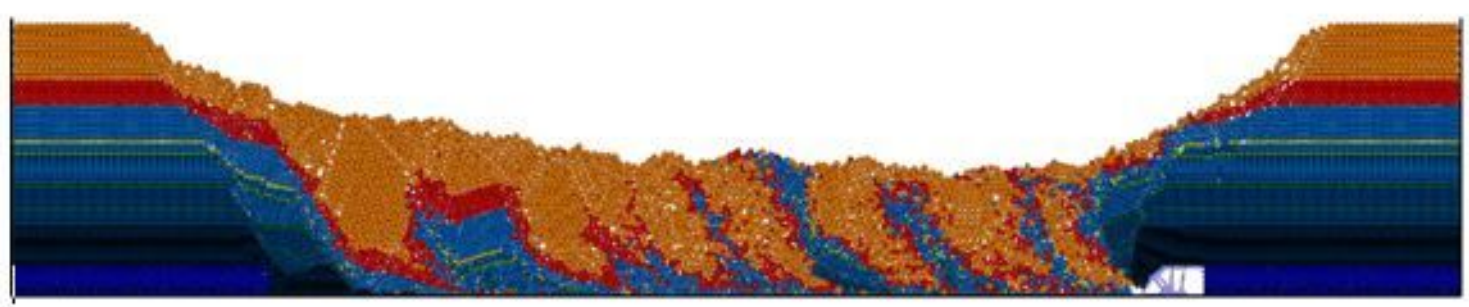

(a) $0.8 \mathrm{~m} \mathrm{TCCI}$

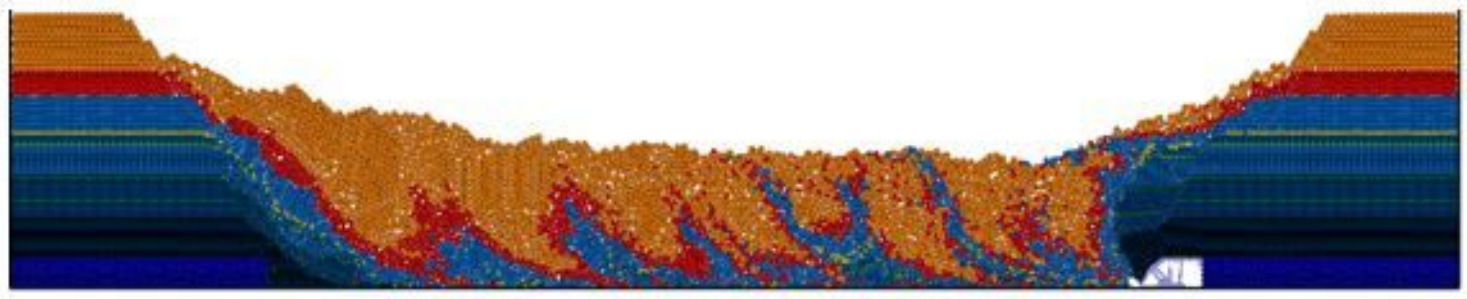

(b) $1.0 \mathrm{~m} \mathrm{TCCI}$

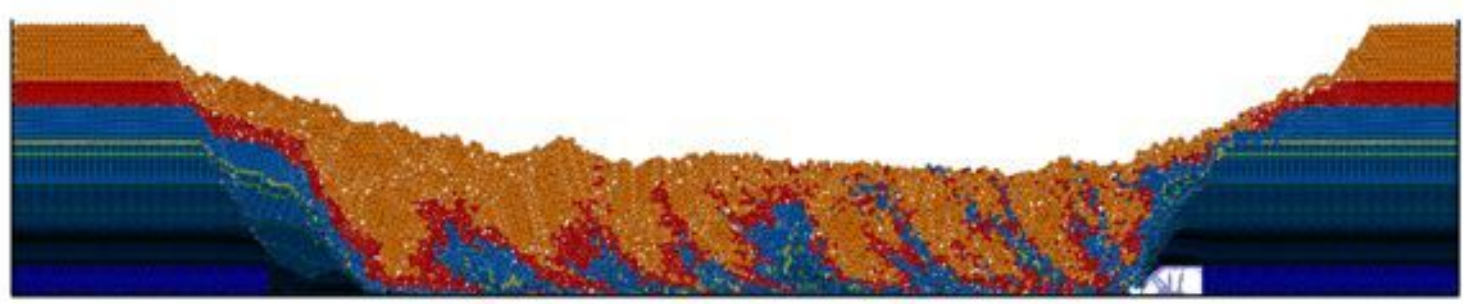

(c) $1.2 \mathrm{~m} \mathrm{TCCI}$

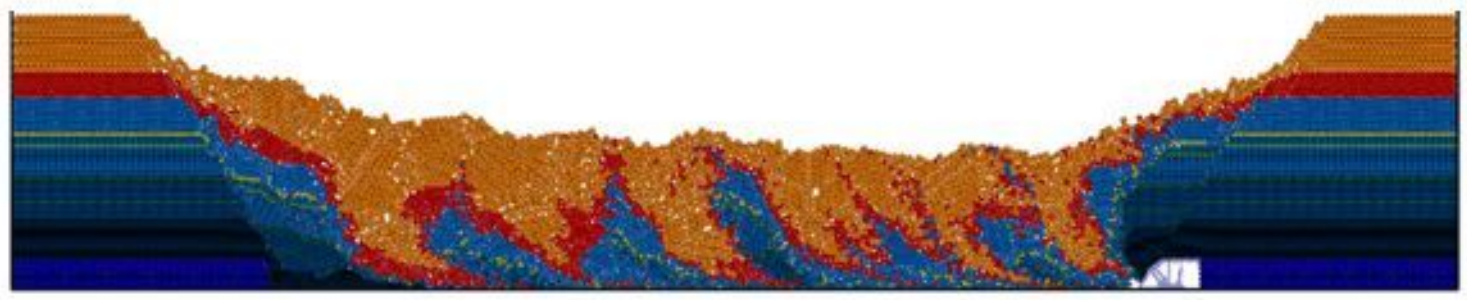

(d) $1.6 \mathrm{~m} \mathrm{TCCI}$

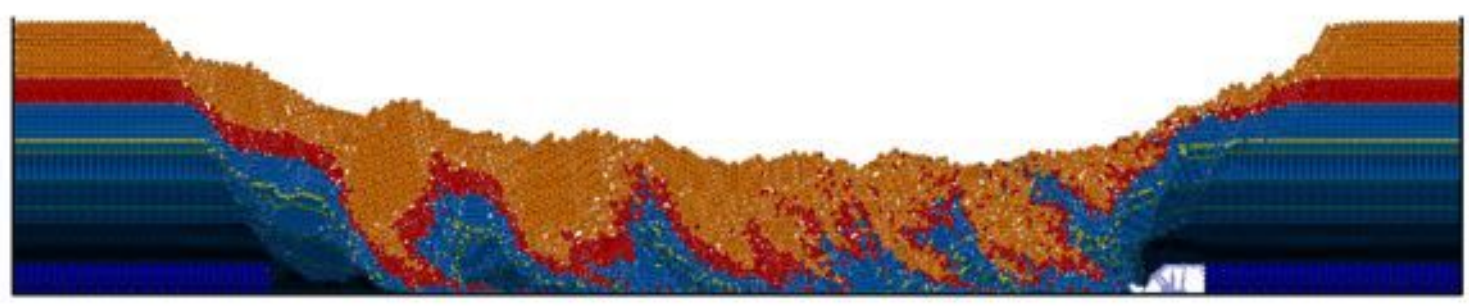

(e) $2.4 \mathrm{~m} \mathrm{TCCI}$

\section{Figure 8}

Loss of top coal in different coal-drawing interval under $20.0 \mathrm{~m}$ top coal thickness 


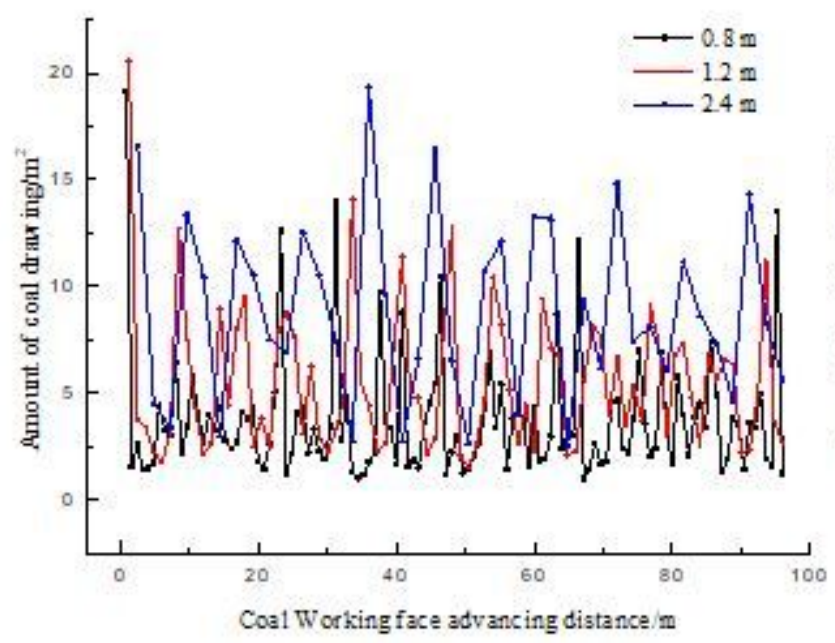

(a) $0.8 \mathrm{~m} 、 1.2 \mathrm{~m} 、 2.4 \mathrm{~m}$ TCCIs

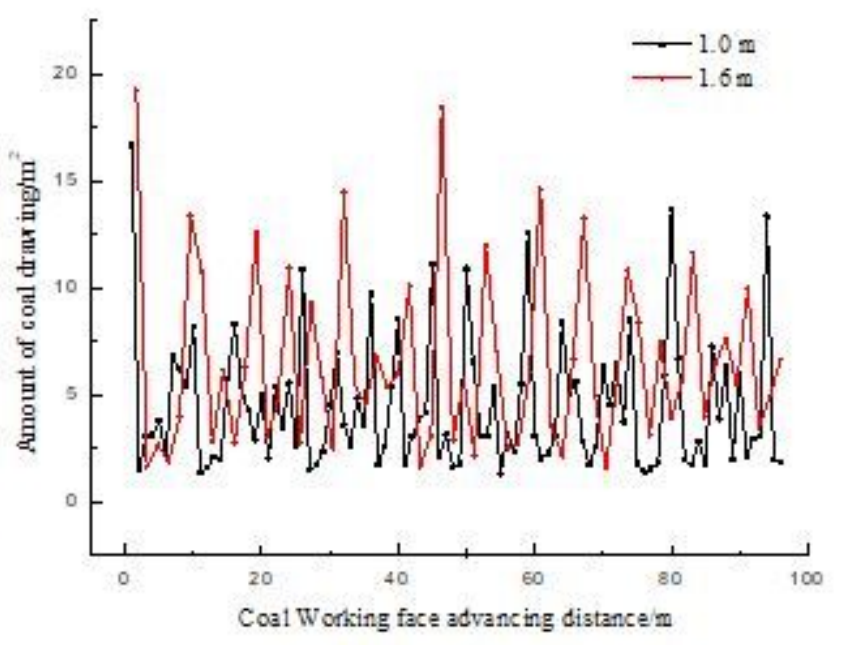

(b) $1.0 \mathrm{~m} 、 1.6 \mathrm{~m}$ TCCIs

Figure 9

Statistics of top coal recovery amount of each step in different coal-drawing interval under $4.0 \mathrm{~m}$ top coal thickness

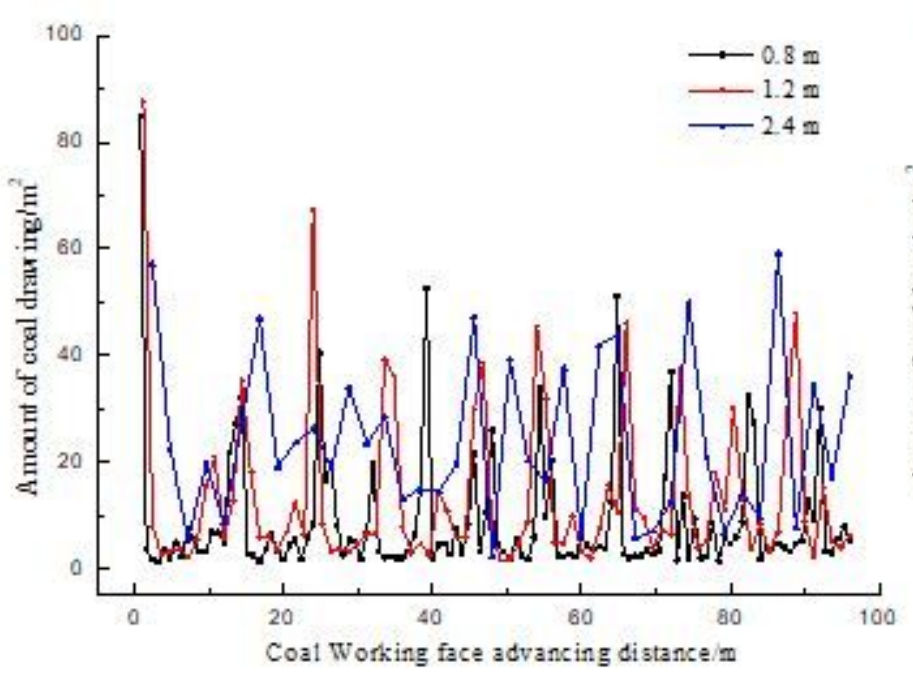

(a) $0.8 \mathrm{~m} 、 1.2 \mathrm{~m} 、 2.4 \mathrm{~m}$ TCCIs

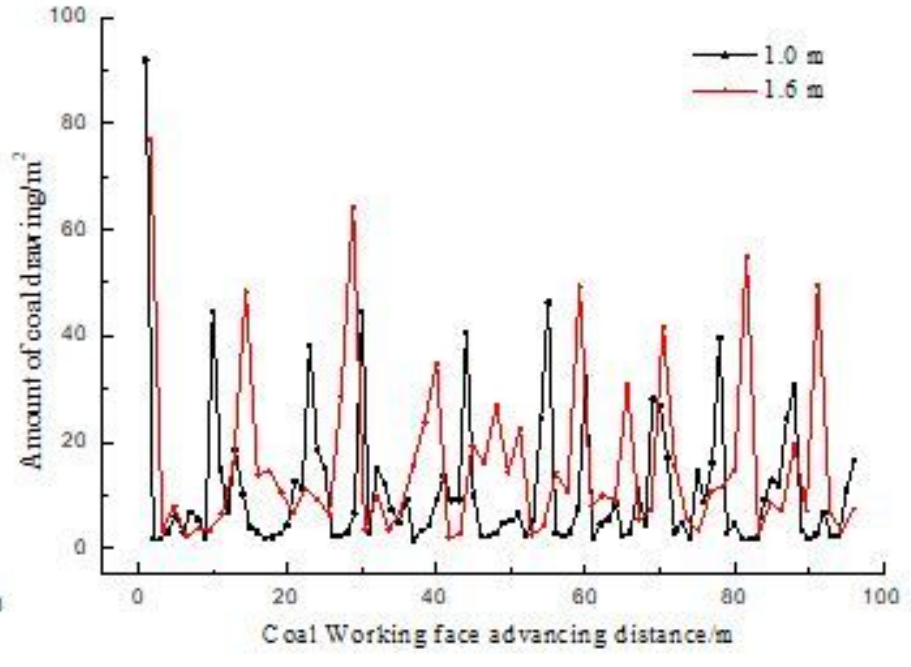

(b) $1.0 \mathrm{~m} 、 1.6 \mathrm{~m}$ TCCIs

Figure 10

Statistics of top coal recovery amount of each step in different coal-drawing interval under $12.0 \mathrm{~m}$ top coal thickness 


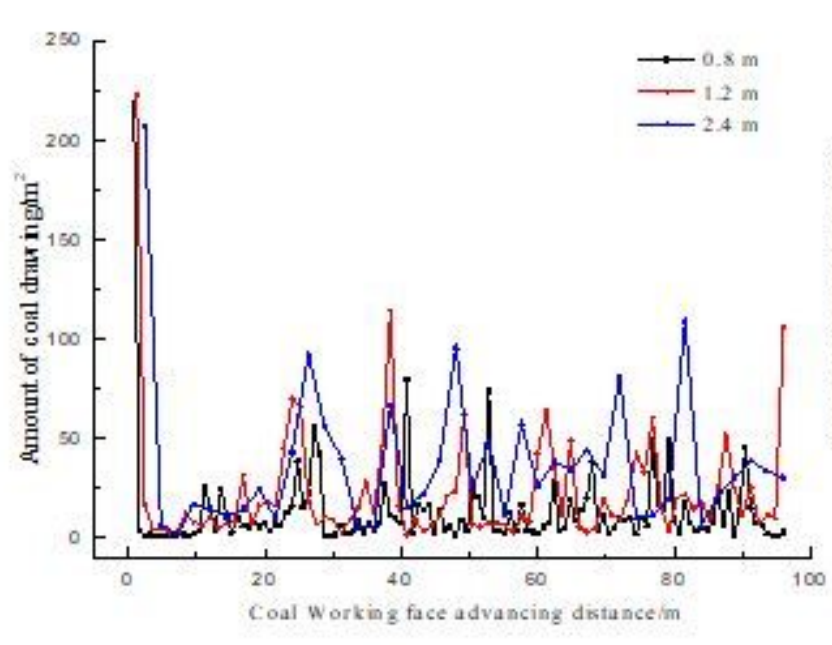

(a) $0.8 \mathrm{~m} 、 1.2 \mathrm{~m} 、 2.4 \mathrm{~m}$ TCCIs

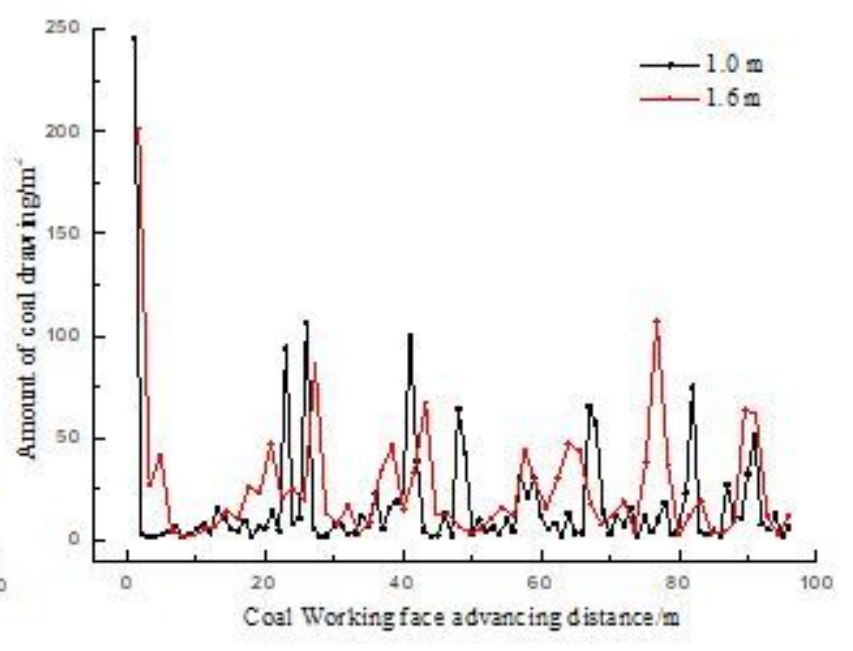

(b) $1.0 \mathrm{~m} 、 1.6 \mathrm{~m}$ TCCIs

\section{Figure 11}

Statistics of top coal recovery amount of each step in different coal-drawing interval under $20.0 \mathrm{~m}$ top coal thickness

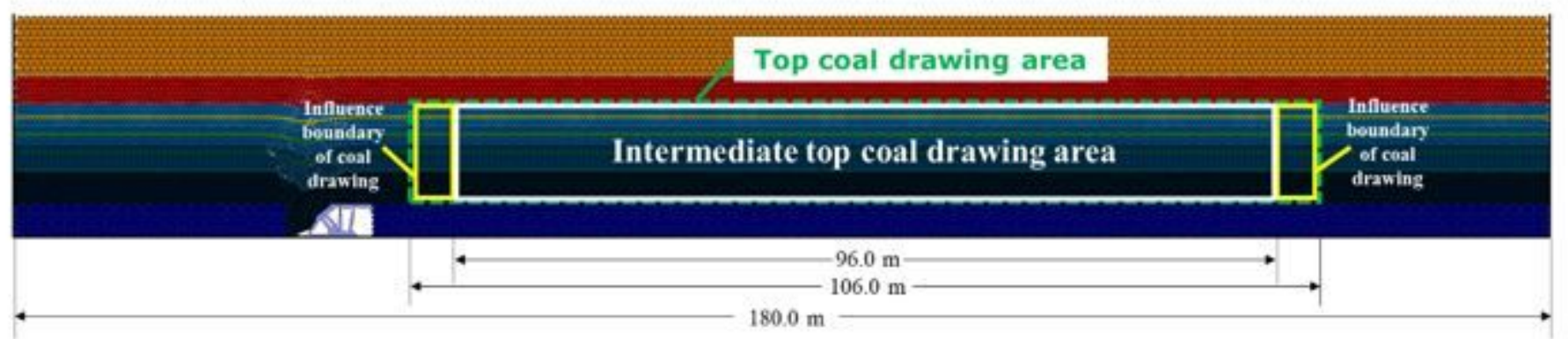

Figure 12

Schematic diagram of the total top coal caving area in the statistics of top coal caving along the strike direction of working face 


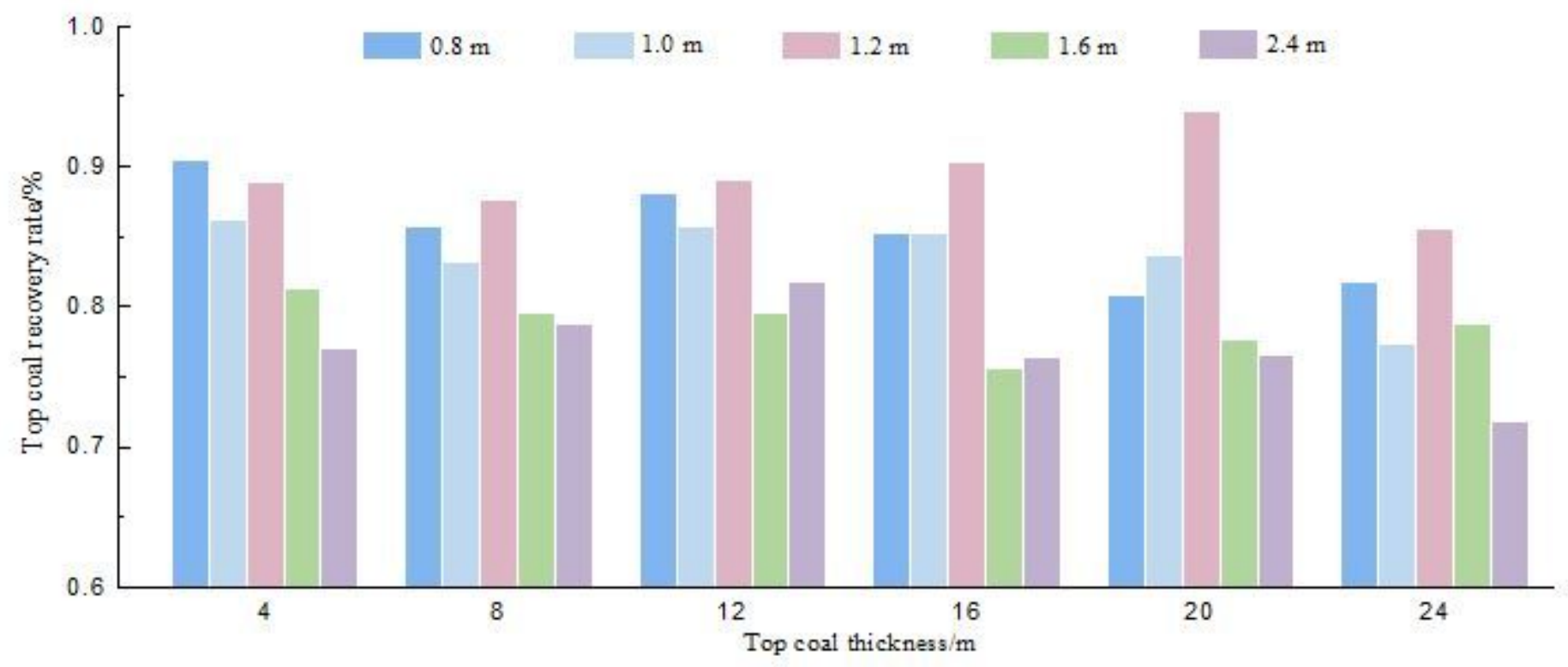

Figure 13

Statistic of top coal recovery rate under different coal-drawing interval and top coal thickness 